\title{
Phase-amplitude model for doubly fed induction generators
}

\author{
Hua HUANG ${ }^{1,2}$, Ping $\mathrm{JU}^{2}$, Xueping $\mathrm{PAN}^{2}$, Yuqing $\mathrm{JIN}^{2}$, \\ Xiaoming YUAN ${ }^{1}$, Yuan GAO ${ }^{2}$
}

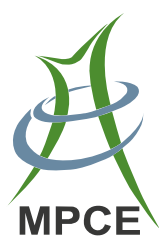

\begin{abstract}
The doubly fed induction generator (DFIG) is major type of wind turbine generator used in grid-connected wind farms. Practical models of DFIG have been built to study the influence of wind power generation on power system dynamics. However, most existing practical models of the DFIG are based on rectangular coordinates, in which frequency variation is neglected. In this paper, a phase-amplitude ( $\mathrm{P}-\mathrm{A})$ model is proposed for a DFIG based on phase and amplitude of the internal voltage. The model structure is much like that of the synchronous generator, and the rotor voltage can manipulate both the amplitude and the phase of the internal voltage.
\end{abstract}

CrossCheck date: 13 July 2018

Received: 30 December 2016/Accepted: 13 July 2018/Published online: 16 October 2018

(C) The Author(s) 2018

$\bowtie$ Ping JU

pju@hhu.edu.cn

Hua HUANG

hua.h@hotmail.com

Xueping PAN

xueping_pan@163.com

Yuqing JIN

jyq16@hhu.edu.cn

Xiaoming YUAN

yuanxm@mail.hust.edu.cn

Yuan GAO

gaoyuan@163.com

1 State Key Laboratory of Advanced Electromagnetic Engineering and Technology, School of Electrical and Electronic Engineering, Huazhong University of Science and Technology, Wuhan 430074, China

2 College of Energy and Electrical Engineering, Hohai University, Nanjing 210098, China
Comparisons have been made between the new $\mathrm{P}-\mathrm{A}$ model of the DFIG and the synchronous generator model, as well as the asynchronous motor model. The contributions of the new P-A model of the DFIG are discussed and it is demonstrated that the proposed model has better ability in describing power system dynamic phenomena such as voltage dynamics and structural dynamics in general. Simulation results and a field test validate these contributions.

Keywords Doubly fed induction generator (DFIG), Model, Internal voltage, Voltage dynamics, Frequency dynamics

\section{Introduction}

With the increasing penetration of wind energy in power systems, their dynamic characteristics need to be investigated $[1,2]$. Doubly fed induction generator (DFIG) is an important subsystem in wind turbine generators (WTGs) $[3,4]$, and modelling of it is essential. Analytical DFIG models, which are represented by flux linkages and rotor speed [5-7], are derived from basic physical principles and have well founded theory. These models are valid for large excursions in frequency and voltage of the system.

Considerable attention has been paid to the practical models of DFIG. Practical models of the DFIG are derived from the analytical models by defining the practical variables. In power system electro-magnetic transient stability studies, DFIG is normally represented by a fifth-order practical model $[8,9]$, which considers both the stator and rotor transients. Neglecting stator transients in the fifthorder model yields a third-order practical model [9, 10], frequently used in power system electro-mechanical 
transient stability studies. If rotor electrical transients are also neglected, the first-order rotor speed model (or twomass drive train model) is obtained and used in conjunction with the circuit representation of the algebraic equations [11-14].

Practical models of the DFIG are usually expressed based on direct and quadrature axes. In $[15,16]$, the internal voltage and phase of the DFIG were calculated and used to design the controller based on flux magnitude and angle control (FMAC) strategy, which adjusts the magnitude of the rotor voltage for the control of electrical power. In [17], a synchronized model of the DFIG was presented and a more simplified control system, which makes the DFIG equivalent to a synchronous generator, was proposed. In the synchronized model of the DFIG, the relation between the electrical power and the magnitude/phase of the internal voltage, and the relation between the rotor voltage and the magnitude/phase of the internal voltage were presented. However, the analytical expression of the dynamic model of the DFIG based on the state variables of magnitude/phase of the internal voltage has not been provided.

The concept of an internal voltage motion equation was proposed recently in $[18,19]$. The relationship between phase-amplitude of the internal voltage and the unbalanced power is analyzed based on the transfer function for smallsignal stability analysis. In [20], a polar angle modelling method for DFIG is presented. Based on [20], a new phaseamplitude ( $\mathrm{P}-\mathrm{A})$ model for the DFIG is proposed. The new model is achieved by redefining the practical variables.

Contributions of the new P-A model for the DFIG are as follows.

1) The P-A model of the DFIG can be used conveniently for power system voltage dynamic analysis and controller design since the state variables of internal voltage and angle are expressed directly by the rotor voltages.

2) Based on the polar form model of the DFIG, the structural dynamics of the DFIG can be illustrated. It indicates that the DFIG is a two time-scale system, where the fast behavior is dominated by the electrical states, and the slow is dominated by the mechanical states.

3) The effects of system frequency are considered in the proposed models.

This paper is organized as follows. The existing modelling method of DFIGs is briefly presented in Section 2. In Section 3, two new third-order models, based on rectangular coordinates and polar coordinates respectively, are proposed. The polar form model of the DFIG is compared with the synchronous generator model and an induction machine in Section 4, and the structural dynamics of the
DFIG are also discussed in Section 4. Simulation results and field tests with a low voltage ride-through experiment are presented and the validation of the proposed model is shown in Section 5.

\section{Existing models for DFIG}

Basically, DFIG is an induction type generator; the equivalent circuit of DFIG is similar to that of an induction machine. In the following, the development of a fifth-order model and a third-order representation of the DFIG are described.

\subsection{Fifth-order model}

DFIG is generally represented by a set of fifth-order differential equations of the flux linkages and shaft speed [9]. According to the standard per-unit notation, the directand quadrature-axis stator and rotor flux linkages are represented in the synchronously-rotating reference frame by:

$$
\left\{\begin{array}{l}
u_{d s}=-R_{s} i_{d s}+\frac{\mathrm{d} \psi_{d s}}{\mathrm{~d} t}-\omega_{s} \psi_{q s} \\
u_{q s}=-R_{s} i_{q s}+\frac{\mathrm{d} \psi_{q s}}{\mathrm{~d} t}+\omega_{s} \psi_{d s} \\
u_{d r}=R_{r} i_{d r}+\frac{\mathrm{d} \psi_{d r}}{\mathrm{~d} t}-\left(\omega_{s}-\omega_{r}\right) \psi_{q r} \\
u_{q r}=R_{r} i_{q r}+\frac{\mathrm{d} \psi_{q r}}{\mathrm{~d} t}+\left(\omega_{s}-\omega_{r}\right) \psi_{d r}
\end{array}\right.
$$

where $\psi_{d s}$ and $\psi_{q s}$ are the $d$-axis and $q$-axis stator flux linkages; $\psi_{d r}$ and $\psi_{q r}$ are the $d$-axis and $q$-axis rotor flux linkages; $u_{d s}$ and $u_{q s}$ are the $d$-axis and $q$-axis stator terminal voltages; $u_{d r}$ and $u_{q r}$ are the $d$-axis and $q$-axis rotor voltages; $\omega_{s}$ and $\omega_{r}$ are the synchronous and rotor phase speed; $R_{s}$ and $R_{r}$ are the stator and rotor resistance.

The flux-current relationships are shown as:

$$
\left\{\begin{array}{l}
\psi_{d s}=-L_{s} i_{d s}+L_{m} i_{d r} \\
\psi_{q s}=-L_{s} i_{q s}+L_{m} i_{q r} \\
\psi_{d r}=L_{r} i_{d r}-L_{m} i_{d s} \\
\psi_{q r}=L_{r} i_{q r}-L_{m} i_{q s}
\end{array}\right.
$$

where $i_{d s}$ and $i_{q s}$ are the $d$-axis and $q$-axis stator currents; $i_{d r}$ and $i_{q r}$ are the $d$-axis and $q$-axis rotor currents; $L_{s}=$ $L_{s \sigma}+L_{m}, L_{r}=L_{r \sigma}+L_{m}, L_{s \sigma}$ is the stator leakage inductance, $L_{r \sigma}$ is the rotor leakage inductance, and $L_{m}$ is the mutual inductance between stator and rotor.

The generator rotor shaft is connected to the turbine shaft flexibly via a gearbox and coupling. The fifth order differential equation describes the wind turbine drive system by a one-mass model, which is shown as:

$2 H \frac{\mathrm{d} \omega_{r}}{\mathrm{~d} t}=T_{m}-T_{e}$ 
where $H=H_{t}+H_{g}, H_{t}$ and $H_{g}$ are the inertial constant of the turbine and the generator; $T_{m}$ is the wind torque, which is the power input of the wind turbine (WT); $T_{e}$ is the electromagnetic torque.

The equation of the electromagnetic torque is:

$$
T_{e}=\psi_{d s} i_{q s}-\psi_{q s} i_{d s}=\psi_{d r} i_{q r}-\psi_{q r} i_{d r}
$$

The model of (2) and (3) is called a fifth-order model. By defining the variables (these defined variables are often called practical variables) as in (5), the practical fifth-order models of the DFIG are obtained [9]. This is shown in (6).

\subsection{Classical third-order model}

In power system electromechanical transient analysis, the stator transient of the DFIG is often neglected by setting $\mathrm{d} \psi_{d s} / \mathrm{d} t=\mathrm{d} \psi_{q s} / \mathrm{d} t=0$. Substitution of (5) and (2) into (1) yields the stator and rotor voltage equations. The stator voltage equations of the DFIG are:

$\left\{\begin{array}{l}u_{d s}=-R_{s} i_{d s}+X^{\prime} i_{q s}+E_{d}^{\prime} \\ u_{q s}=-R_{s} i_{q s}-X^{\prime} i_{d s}+E_{q}^{\prime}\end{array}\right.$

The rotor voltage equations can be expressed as:

$$
\left\{\begin{array}{l}
u_{d r}=\frac{1}{T_{0}^{\prime}}\left(\frac{L_{r}}{\omega_{s} L_{m}} E_{q}^{\prime}+L_{m} i_{d s}\right)+\frac{\mathrm{d}}{\mathrm{d} t}\left(\frac{L_{r}}{\omega_{s} L_{m}} E_{q}^{\prime}\right)+\left(\omega_{s}-\omega_{r}\right) \frac{L_{r}}{\omega_{s} L_{m}} E_{d}^{\prime} \\
u_{q r}=\frac{1}{T_{0}^{\prime}}\left(\frac{L_{r}}{\omega_{s} L_{m}} E_{d}^{\prime}-L_{m} i_{q s}\right)+\frac{\mathrm{d}}{\mathrm{d} t}\left(\frac{L_{r}}{\omega_{s} L_{m}} E_{d}^{\prime}\right)-\left(\omega_{s}-\omega_{r}\right) \frac{L_{r}}{\omega_{s} L_{m}} E_{q}^{\prime}
\end{array}\right.
$$

$$
\left\{\begin{array}{l}
E_{d}^{\prime}=-\frac{\omega_{s} L_{m}}{L_{r}} \psi_{q r} \\
E_{q}^{\prime}=\frac{\omega_{s} L_{m}}{L_{r}} \psi_{d r} \\
X=\omega_{s} L_{s} \\
X^{\prime}=\omega_{s}\left(L_{s}-\frac{L_{m}^{2}}{L_{r}}\right) \\
T_{0}^{\prime}=\frac{L_{r}}{R_{r}}
\end{array}\right.
$$

where $E_{d}^{\prime}$ and $E_{q}^{\prime}$ are the $d$-axis and $q$-axis voltages behind the transient reactance; $X_{s}$ is the stator reactance; $X_{s}^{\prime}$ is the stator transient reactance; $T_{0}^{\prime}$ is the rotor circuit time constant.

$$
\left\{\begin{array}{l}
\frac{X_{s}^{\prime} \mathrm{d} i_{d s}}{\omega_{s}} \frac{\mathrm{d} t}{}=v_{d s}-\left[R_{s}+\frac{1}{\omega_{s} T_{0}^{\prime}}\left(X_{s}-X_{s}^{\prime}\right)\right] i_{d s} \\
\quad-(1-s) E_{d}^{\prime}-\frac{L_{m}}{L_{r}} v_{d r}+\frac{1}{\omega_{s} T_{0}^{\prime}} E_{q}^{\prime}+X_{s}^{\prime} i_{q s} \\
\frac{X_{s}^{\prime} \mathrm{d} i_{q s}}{\omega_{s}}=v_{q s}-\left[R_{s}+\frac{1}{\omega_{s} T_{0}^{\prime}}\left(X_{s}-X_{s}^{\prime}\right)\right] i_{q s} \\
\quad-(1-s) E_{q}^{\prime}-\frac{L_{m}}{L_{r}} v_{q r}-\frac{1}{\omega_{s} T_{0}^{\prime}} E_{d}^{\prime}-X_{s}^{\prime} i_{d s} \\
\frac{\mathrm{d} E_{d}^{\prime}}{\mathrm{d} t}=s \omega_{s} E_{q}^{\prime}-\omega_{s} \frac{L_{m}}{L_{r}} v_{q r}-\frac{1}{T_{0}^{\prime}}\left[E_{d}^{\prime}+\left(X_{s}-X_{s}^{\prime}\right) i_{q s}\right] \\
\frac{\mathrm{d} E_{q}^{\prime}}{\mathrm{d} t}=-s \omega_{s} E_{d}^{\prime}+\omega_{s} \frac{L_{m}}{L_{r}} v_{d r}-\frac{1}{T_{0}^{\prime}}\left[E_{q}^{\prime}-\left(X_{s}-X_{s}^{\prime}\right) i_{d s}\right]
\end{array}\right.
$$

where $s$ is the slip, which is defined as $s=\left(\omega_{s}-\omega_{r}\right) / \omega_{s}$.

The fifth-order model of the DFIG considers both the stator dynamics and rotor dynamics. This is often used in power system electromagnetic transient analysis.
The rotor voltage equations widely used in the literature are expressed as:

$$
\left\{\begin{array}{l}
\frac{\mathrm{d} E_{d}^{\prime}}{\mathrm{d} t}=-\frac{1}{T_{0}^{\prime}}\left[E_{d}^{\prime}-\left(X-X^{\prime}\right) i_{q s}\right]+s \omega_{s} E_{q}^{\prime}-\omega_{s} u_{q r}^{\prime} \\
\frac{\mathrm{d} E_{q}^{\prime}}{\mathrm{d} t}=-\frac{1}{T_{0}^{\prime}}\left[E_{q}^{\prime}+\left(X-X^{\prime}\right) i_{d s}\right]-s \omega_{s} E_{d}^{\prime}+\omega_{s} u_{d r}^{\prime}
\end{array}\right.
$$

where

$$
\left\{\begin{array}{l}
u_{d r}^{\prime}=\left(L_{m} / L_{r}\right) u_{d r} \\
u_{q r}^{\prime}=\left(L_{m} / L_{r}\right) u_{q r}
\end{array}\right.
$$

\subsection{Third-order model including system frequency dynamics}

During a severe system fault, power systems may experience large excursions of frequency. The first term of (8) should be expressed as follows when the system frequency dynamics are included.

$$
\left\{\begin{array}{l}
\frac{\mathrm{d}}{\mathrm{d} t}\left(\frac{L_{r}}{\omega_{s} L_{m}} E_{q}^{\prime}\right)=\frac{L_{r}}{L_{m}}\left(\frac{1}{\omega_{s}} \frac{\mathrm{d} E_{q}^{\prime}}{\mathrm{d} t}-\frac{E_{q}^{\prime}}{\omega_{s}^{2}} \frac{\mathrm{d} \omega_{s}}{\mathrm{~d} t}\right) \\
\frac{\mathrm{d}}{\mathrm{d} t}\left(\frac{L_{r}}{\omega_{s} L_{m}} E_{d}^{\prime}\right)=\frac{L_{r}}{L_{m}}\left(\frac{1}{\omega_{s}} \frac{\mathrm{d} E_{d}^{\prime}}{\mathrm{d} t}-\frac{E_{d}^{\prime}}{\omega_{s}^{2}} \frac{\mathrm{d} \omega_{s}}{\mathrm{~d} t}\right)
\end{array}\right.
$$

The rotor voltage equations should be expressed as follows by substituting (11) into (8).

$$
\left\{\begin{array}{l}
\frac{\mathrm{d} E_{d}^{\prime}}{\mathrm{d} t}=-\frac{1}{T_{0}^{\prime}}\left[E_{d}^{\prime}-\left(X-X^{\prime}\right) i_{q s}\right]+s \omega_{s} E_{q}^{\prime}-\omega_{s} u_{q r}^{\prime}+\frac{E_{d}^{\prime}}{\omega_{s}} \frac{\mathrm{d} \omega_{s}}{\mathrm{~d} t} \\
\frac{\mathrm{d} E_{q}^{\prime}}{\mathrm{d} t}=-\frac{1}{T_{0}^{\prime}}\left[E_{q}^{\prime}+\left(X-X^{\prime}\right) i_{d s}\right]-s \omega_{s} E_{d}^{\prime}+\omega_{s} u_{d r}^{\prime}+\frac{E_{q}^{\prime}}{\omega_{s}} \frac{\mathrm{d} \omega_{s}}{\mathrm{~d} t}
\end{array}\right.
$$

Using the same method as above, the model of (6) can 
be rewritten by including the effects of the system frequency variations. It can be seen from (6) and (10) that the system frequency dynamics are neglected in the existing practical models of the DFIG. This is reasonable when the power system is very large and the system frequency is considered to be constant during disturbances. However, if the studied system is very small, the system frequency may experience large excursions during a severe fault. In this situation, the model of (12) should be applied by including the system frequency dynamics.

\section{P-A models for DFIG}

In this section, the practical variables are redefined, and two kinds of DFIG models are proposed.

\subsection{Proposed model of DFIG based on rectangular coordinates}

Redefine the practical variables as in (13).

$$
\left\{\begin{array}{l}
E_{d}^{\prime}=-\frac{L_{m}}{L_{r}} \psi_{q r} \\
E_{q}^{\prime}=\frac{L_{m}}{L_{r}} \psi_{d r} \\
L=L_{s} \\
L^{\prime}=L_{s}-\frac{L_{m}^{2}}{L_{r}}
\end{array}\right.
$$

Substitution of (13) and (2) into (1) yields the new stator and rotor voltage equations. The stator voltage equations are:

$\left\{\begin{array}{l}u_{d s}=-R_{s} i_{d s}+\omega_{s} L^{\prime} i_{q s}+\omega_{s} E_{d}^{\prime} \\ u_{q s}=-R_{s} i_{q s}-\omega_{s} L^{\prime} i_{d s}+\omega_{s} E_{q}^{\prime}\end{array}\right.$

and the rotor voltage equations are as follows, in which the dynamics of frequency are included.

$$
\left\{\begin{array}{l}
\frac{\mathrm{d} E_{d}^{\prime}}{\mathrm{d} t}=-\frac{1}{T_{0}^{\prime}}\left[E_{d}^{\prime}-\left(L-L^{\prime}\right) i_{q s}\right]+s \omega_{s} E_{q}^{\prime}-u_{q r}^{\prime} \\
\frac{\mathrm{d} E_{q}^{\prime}}{\mathrm{d} t}=-\frac{1}{T_{0}^{\prime}}\left[E_{q}^{\prime}+\left(L-L^{\prime}\right) i_{d s}\right]-s \omega_{s} E_{d}^{\prime}+u_{d r}^{\prime}
\end{array}\right.
$$

The equation of the electromagnetic torque is:

$$
T_{e}=E_{d}^{\prime} i_{d s}+E_{q}^{\prime} i_{q s}
$$

\subsection{Proposed model of DFIG based on polar coordinates}

In the following, the polar form model of the DFIG is deduced from the proposed DFIG model based on rectangular coordinates.

\subsubsection{Phasor relationship between different voltages}

Conversion of the following variables from rectangular coordinates to polar coordinates.

$\left\{\begin{array}{l}\dot{U}=u_{d s}+\mathrm{j} u_{q s} \\ \dot{E}^{\prime}=E_{d}^{\prime}+\mathrm{j} E_{q}^{\prime} \\ \dot{I}=i_{d s}+\mathrm{j} i_{q s}\end{array}\right.$

Suppose the imaginary axis $j$ overlaps the $q$-axis, and the real axis $r$ overlaps the $d$-axis. The $\alpha$ is defined as the phase between the phasor $\dot{U}$ and the $d$-axis. $\beta$ is the phase between the phasor $\dot{E}^{\prime}$ and the $d$-axis, and $\delta$ is the phase between the phasor $\dot{E}^{\prime}$ and $\dot{U}$.

$\left\{\begin{array}{l}\delta=\beta-\alpha \\ u_{d s}=U \cos \alpha \\ u_{q s}=U \sin \alpha \\ E_{d}^{\prime}=E^{\prime} \cos \beta \\ E_{q}^{\prime}=E^{\prime} \sin \beta\end{array}\right.$

The phasor relationships between different voltages are shown in Fig. 1.

\subsubsection{Stator voltage equation in phasor form}

Using phasors of (18), we can replace (14) by:

$\dot{U}=\omega_{s} \dot{E}^{\prime}-\left(r_{s}+\mathrm{j} \omega_{s} L^{\prime}\right) \dot{I}=\omega_{s} \dot{E}^{\prime}-Z_{s} \dot{I}$

Figure 2 is the equivalent circuit corresponding to (19).

\subsubsection{Internal voltage equation in polar form}

The derivation of internal voltages can be expressed as follows based on (18).

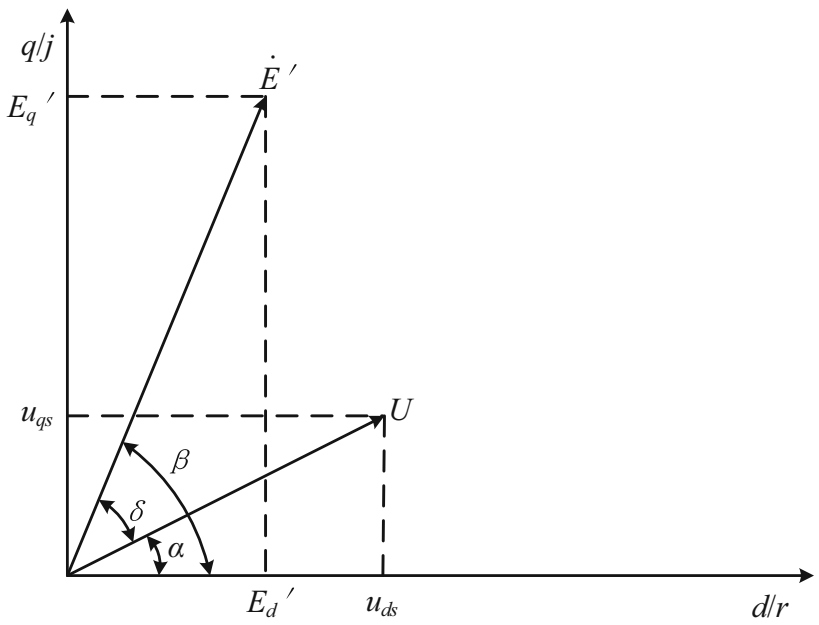

Fig. 1 Phasor relationship between different voltages 


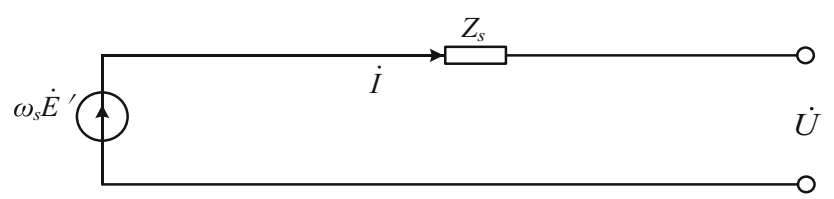

Fig. 2 Equivalent circuit of stator voltage

$\left\{\begin{array}{l}\frac{\mathrm{d} E_{d}^{\prime}}{\mathrm{d} t}=\frac{\mathrm{d}\left(E^{\prime} \cos \beta\right)}{\mathrm{d} t}=\frac{\mathrm{d} E^{\prime}}{\mathrm{d} t} \cos \beta-E^{\prime} \sin \beta \frac{\mathrm{d} \beta}{\mathrm{d} t} \\ \frac{\mathrm{d} E_{q}^{\prime}}{\mathrm{d} t}=\frac{\mathrm{d}\left(E^{\prime} \sin \beta\right)}{\mathrm{d} t}=\frac{\mathrm{d} E^{\prime}}{\mathrm{d} t} \sin \beta+E^{\prime} \cos \beta \frac{\mathrm{d} \beta}{\mathrm{d} t}\end{array}\right.$

Substituting (20) into (15), the phasor form of (15) can be attained by adding $\mathrm{d} E_{d}^{\prime} / \mathrm{d} t$ times $\cos \beta$ to $\mathrm{d} E_{q}^{\prime} / \mathrm{d} t$ times $\sin \beta$.

$$
\begin{aligned}
T_{0}^{\prime} \frac{\mathrm{d} E^{\prime}}{\mathrm{d} t}= & -E^{\prime}+\left(L-L^{\prime}\right)\left(i_{q s} \cos \beta-i_{d s} \sin \beta\right) \\
& +T_{0}^{\prime}\left(-u_{q r}^{\prime} \cos \beta+u_{d r}^{\prime} \sin \beta\right)
\end{aligned}
$$

Similarly, (15) will be transformed as follows by subtracting $\mathrm{d} E_{d}^{\prime} / \mathrm{d} t$ times $\sin \beta$ from $\mathrm{d} E_{q}^{\prime} / \mathrm{d} t$ times $\cos \beta$.

$$
\begin{aligned}
T_{0}^{\prime} E^{\prime} \frac{\mathrm{d} \beta}{\mathrm{d} t}= & -\left(L-L^{\prime}\right)\left(i_{d s} \cos \beta+i_{q s} \sin \beta\right) \\
& -T_{0}^{\prime} s \omega_{s} E^{\prime}+T_{0}^{\prime}\left(u_{d r}^{\prime} \cos \beta+u_{q r}^{\prime} \sin \beta\right)
\end{aligned}
$$

Since the stator resistance is very small, the stator currents can be expressed as in (23) by setting $R_{s}=0$ in (14).

$$
\left\{\begin{array}{l}
i_{d s}=\frac{E^{\prime} \sin \beta-U \sin \alpha / \omega_{s}}{L^{\prime}} \\
i_{q s}=\frac{U \cos \alpha / \omega_{s}-E^{\prime} \cos \beta}{L^{\prime}}
\end{array}\right.
$$

The following two expressions can be obtained from (23).

$$
\left\{\begin{array}{l}
i_{q s} \cos \beta-i_{d s} \sin \beta=-\frac{E^{\prime}}{L^{\prime}}+\frac{U}{\omega_{s} L^{\prime}} \cos \delta \\
i_{d s} \cos \beta+i_{q s} \sin \beta=\frac{U}{\omega_{s} L^{\prime}} \sin \delta
\end{array}\right.
$$

Let $C=\frac{L-L^{\prime}}{L}, T^{\prime}=T_{0}^{\prime} \frac{L^{\prime}}{L}$. The following will be obtained by substituting (24) into (22).

$\frac{\mathrm{d} \beta}{\mathrm{d} t}=\left(\omega_{r}-\omega_{s}\right)-\left(\frac{C U}{T^{\prime} \omega_{s} E^{\prime}}\right) \sin \delta+\frac{u_{d r}^{\prime} \cos \beta+u_{q r}^{\prime} \sin \beta}{E^{\prime}}$

Because the phasor $\dot{U}$ and the $d$-axis are synchronous, $\alpha$ is constant. The derivation of $\delta$ is:

$$
\frac{\mathrm{d} \delta}{\mathrm{d} t}=\frac{\mathrm{d} \beta}{\mathrm{d} t}=\left(\omega_{r}-\omega_{s}\right)-\left(\frac{C U}{T^{\prime} \omega_{s} E^{\prime}}\right) \sin \delta+\frac{u_{d r}^{\prime} \cos \beta+u_{q r}^{\prime} \sin \beta}{E^{\prime}}
$$

The electromagnetic torque can be expressed as follows by substituting (18) and (24) into (16).
$T_{e}=\frac{E^{\prime} U}{\omega_{s} L^{\prime}} \sin (\beta-\alpha)=\frac{E^{\prime} U}{\omega_{s} L^{\prime}} \sin \delta$

The polar form of third-order DFIG model can be rewritten as:

$\left\{\begin{array}{l}T^{\prime} \frac{\mathrm{d} E^{\prime}}{\mathrm{d} t}=-E^{\prime}+\left(\frac{C U}{\omega_{s}}\right) \cos \delta+T^{\prime}\left(u_{d r}^{\prime} \sin \beta-u_{q r}^{\prime} \cos \beta\right) \\ \frac{\mathrm{d} \delta}{\mathrm{d} t}=\left(\omega_{r}-\omega_{s}\right)-\left(\frac{C U}{T^{\prime} \omega_{s} E^{\prime}}\right) \sin \delta+\frac{u_{d r}^{\prime} \cos \beta+u_{q r}^{\prime} \sin \beta}{E^{\prime}} \\ 2 H \frac{\mathrm{d} \omega_{r}}{\mathrm{~d} t}=T_{m}-\left(\frac{E^{\prime} U}{X^{\prime}}\right) \sin \delta\end{array}\right.$

where $X^{\prime}=\omega_{s} L^{\prime}$.

In a DFIG-based wind turbine, the $u_{d s}$ (or $u_{q s}$ ) is located on the $d$-axis (or $q$-axis) because of the flux orientation vector control technique [21]. Therefore, the following conditions will be met:

$$
\left\{\begin{array}{l}
\alpha=0 \\
\beta=\delta \\
u_{d s}=U \\
u_{q s}=0
\end{array}\right.
$$

The terms concerning $\beta$ in (28) can be transformed as:

$$
\left\{\begin{array}{l}
u_{d r}^{\prime} \sin \beta-u_{q r}^{\prime} \cos \beta=\frac{L_{m}}{L_{r}}\left(u_{d r} \sin \delta-u_{q r} \cos \delta\right) \\
u_{d r}^{\prime} \cos \beta+u_{q r}^{\prime} \sin \beta=\frac{L_{m}}{L_{r}}\left(u_{d r} \cos \delta+u_{q r} \sin \delta\right)
\end{array}\right.
$$

As the phase and amplitude of the internal voltage are taken as the state variables in the model, so the model is referred to as an internal voltage phase-amplitude model or $\mathrm{P}-\mathrm{A}$ model.

\section{Model discussions}

It can be seen from (14) and (15) that the proposed DFIG model based on rectangular coordinates has the same model structure as the existing models expressed by (7) and (10). However, the proposed models in (14) and (15) have the advantage of taking into account the effects of system frequency without adding the term of $\mathrm{d} \omega_{s} / \mathrm{d} t$ to the equations.

The proposed $\mathrm{P}-\mathrm{A}$ model of DFIG has a similar model structure to the synchronous generator and the induction motor. This is discussed in detail in the following.

\subsection{Comparisons with synchronous generator equation}

The third-order model of a synchronous generator [22] can be written as: 


$$
\left\{\begin{array}{l}
T^{\prime} \frac{\mathrm{d} E^{\prime}}{\mathrm{d} t}=-E^{\prime}+\left(\frac{C U}{\omega_{s}}\right) \cos \delta+E_{f}^{\prime} \\
\frac{\mathrm{d} \delta}{\mathrm{d} t}=\omega_{r}-\omega_{s} \\
2 H \frac{\mathrm{d} \omega_{r}}{\mathrm{~d} t}=T_{m}-\left(\frac{E^{\prime} U}{X^{\prime}}\right) \sin \delta
\end{array}\right.
$$

where $E^{\prime}$ is the voltage behind the transient reactance; $E_{f}^{\prime}$ is the voltage of exciter; $C$ is the constant.

The model of the DFIG in (28) presents some striking similarities with a one-axis model of a synchronous generator in (31) with the following differences:

1) The phase of the DFIG is not a rotation phase of the shaft, but the phase of the rotor flux amplitude with respect to the synchronously-rotating reference frame.

2) There are two extra terms in the phase equation of the DFIG as compared with that of a synchronous machine. The first term is due to the variable speed operation of the induction machine, and the second term is due to excitation effects. Therefore, the DFIG's phase can be controlled directly by the excitation voltage, whereas the phase $\delta$ of synchronous generator cannot.

\subsection{Comparisons with induction motor equation}

A polar form model of the induction machine was proposed in [22]. This is shown in (32).

$$
\left\{\begin{array}{l}
T^{\prime} \frac{\mathrm{d} E^{\prime}}{\mathrm{d} t}=-E^{\prime}+C U \cos \delta \\
\frac{\mathrm{d} \delta}{\mathrm{d} t}=\left(\omega_{r}-\omega_{s}\right)-\left(\frac{C U}{T^{\prime} E^{\prime}}\right) \sin \delta \\
2 H \frac{\mathrm{d} \omega_{r}}{\mathrm{~d} t}=-\left(\frac{E^{\prime} U}{X^{\prime}}\right) \sin \delta-T_{m}
\end{array}\right.
$$

It can be seen from (28) and (32) that there is an extra term in the equations of $E^{\prime}$ and $\delta$ in the DFIG model. This is attributed to the excitation effects in DFIG-based WTGs.

\subsection{Structural dynamic analysis of DFIG based on proposed polar form model}

The structural modelling method, which applied integral manifold theory to describe the dominant dynamic behavior of small and large induction machines, was used in [23]. Based on the DFIG's P-A model, its structural model is proposed for analyzing the DFIG's dominant dynamics.

From the polar form model of the induction machines in [23], it was found that the parameters have the relations of $2 H X^{\prime}<T^{\prime}<\sqrt{2 H X^{\prime}}$ for small induction machines, while $2 H X^{\prime}<\sqrt{2 H X^{\prime}}<T^{\prime}$ for the large ones. Structural dynamics of small and large induction machines were investigated based on integral manifolds, and it was shown that the dynamics of the small induction machine are governed by the speed model, while the dynamics of the large machines are dominated by the voltage equation.

Basically, a DFIG is an induction type generator with its rotor voltage controlled by converter controllers. Using the same analysis method as in [20], the structural dynamics of the DFIG based on the polar from model are investigated. The DFIG's parameters from three wind turbine manufacturers in China are listed in Appendix A Table A1, and the values of parameters $2 H X^{\prime}, \sqrt{2 H X^{\prime}}, T_{0}^{\prime}$ and $T^{\prime}$ are calculated and listed in Table 1.

It can be seen from Table 1 that the relations of $2 H X^{\prime}<T^{\prime}<$ $\sqrt{2 H X^{\prime}}$ are available for the DFIGs. Therefore, a two time-scale singularly perturbed model can be obtained based on (28) by rescaling the speed variables of $\Omega_{r}=T^{\prime} \omega_{r}$ and $\Omega_{s}=T^{\prime} \omega_{s}$, and the small parameter is $\varepsilon=T^{2} /\left(2 H X^{\prime}\right)$. Equation (28) can be rewritten as:

$$
\left\{\begin{array}{l}
\varepsilon \frac{\mathrm{d} E^{\prime}}{\mathrm{d} t}=-\frac{T^{\prime}}{2 H X^{\prime}} E^{\prime}+\varepsilon\left(\frac{C U}{\Omega_{s}}\right) \cos \delta \\
+\varepsilon\left(u_{d r}^{\prime} \sin \beta-u_{q r}^{\prime} \cos \beta\right) \\
\varepsilon \frac{\mathrm{d} \delta}{\mathrm{d} t}=\frac{T^{\prime}}{2 H X^{\prime}}\left(\Omega_{r}-\Omega_{s}\right)-\varepsilon\left(\frac{C U}{\Omega_{s} E^{\prime}}\right) \sin \delta \\
+\varepsilon \frac{u_{d r}^{\prime} \cos \beta+u_{q r}^{\prime} \sin \beta}{E^{\prime}} \\
\frac{\mathrm{d} \omega_{r}}{\mathrm{~d} t}=\frac{1}{2 H} T_{m}-\left(\frac{E^{\prime} U}{2 H X^{\prime}}\right) \sin \delta
\end{array}\right.
$$

Based on singular perturbation theory, it can be concluded from (33) that the DFIG is a two time-scale system, where the fast states are $E^{\prime}$ and $\delta$, and the slow one is $\omega_{r}$. Therefore, the structural dynamics of the DFIG can be obtained conveniently based on the polar form model of the DFIG.

Based on the structural dynamics of the DFIG, it can be seen that the DFIG's mechanical dynamics and the electrical dynamics are decoupling, which is different from synchronous generators, which are dominated by electromechanical dynamics. This is consistent with the common knowledge that the dynamic behavior of a type- 3 WTG is dominated by controller response rather than physical characteristics [24].

Table 1 Parameter values of DFIGs from three different manufacturers

\begin{tabular}{lllll}
\hline Manufacturer & $2 H X^{\prime}$ & $\sqrt{2 H X^{\prime}}$ & $T_{0}^{\prime}$ & $T^{\prime}$ \\
\hline 1 & 0.0169 & 0.1300 & 2.2131 & 0.0954 \\
2 & 0.0200 & 0.1414 & 2.4950 & 0.1197 \\
3 & 0.0229 & 0.1514 & 2.1326 & 0.1131 \\
\hline
\end{tabular}




\section{Simulation results and field test}

The proposed polar form model of the DFIG is beneficial for the structural dynamic analysis of the DFIG, and is also helpful for power system stability studies. In the following, the simulation and field test are carried out, and the responses are obtained to illustrate these contributions.

\subsection{Simulation results}

The simulation analysis is conducted based on MATLAB /Simulink. Figure 3 shows the schematic diagram of the simulation system. It consists of a wind farm

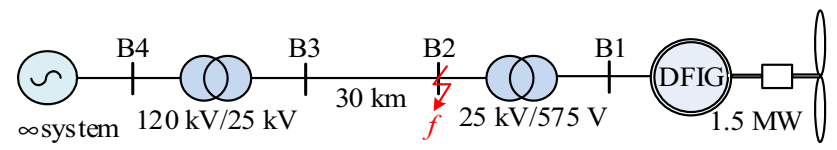

Fig. 3 Structure of test system
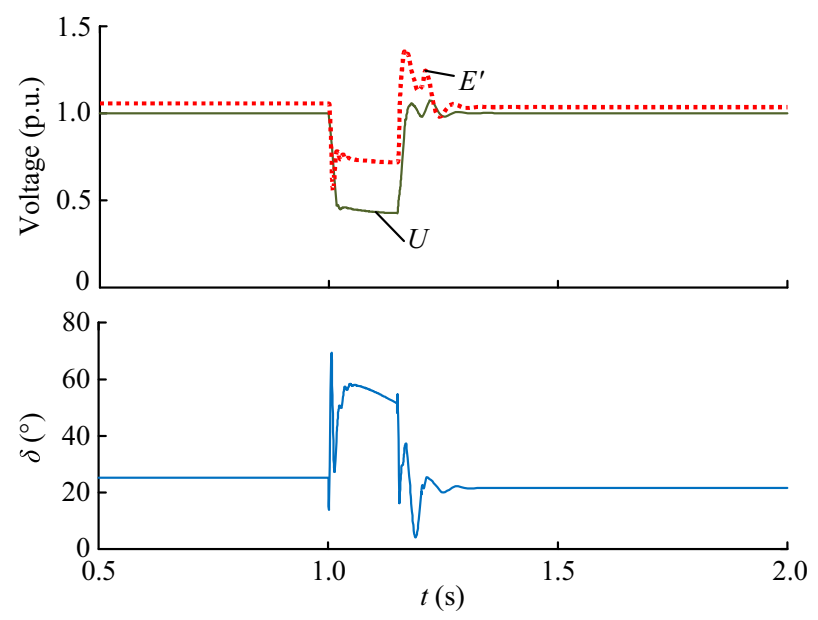

(a) Magnitude of terminal voltage, and the magnitude and angle of the internal voltage
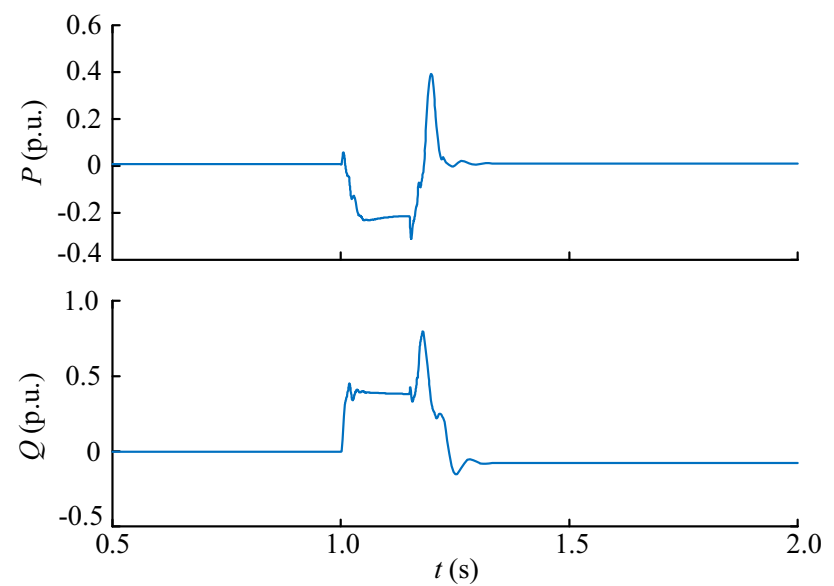

(b) Active power and reactive power

Fig. 4 Responses of DFIG under voltage dip disturbance with six 1.5 MW DFIG-based WTGs connected to a $25 \mathrm{kV}$ distribution system, which exports power to a $120 \mathrm{kV}$ grid through a $30 \mathrm{~km}$ transmission line. The details of the system can be found in the Demo of MATLAB [25].

At $t=1 \mathrm{~s}$, disturbances with different voltage sag depth are applied at the terminal of the DFIG-based WTG, and the fault is cleared at $t=1.15 \mathrm{~s}$ with the system back to its original state. The disturbed trajectories of voltage amplitude and phase angle, active power $P$ and reactive power $Q$ under voltage sag (voltage magnitude drops to $40 \% U_{N}$ ) are shown in Fig. 4.

The second sub-term $\left(C U / \omega_{s}\right) \cos \delta$ and the third subterm $T^{\prime}\left(u_{d r}^{\prime} \sin \beta-u_{q r}^{\prime} \cos \beta\right)$ on the right side of the amplitude equation are shown in Fig. 5a; the second subterm $-\left(\frac{C U}{T^{\prime} \omega_{s} E^{\prime}}\right) \sin \delta$ and the third sub-term $\frac{u_{d r}^{\prime} \cos \beta+u_{q r}^{\prime} \sin \beta}{E^{\prime}}$ on the right side of the phase equation are shown in Fig. $5 \mathrm{~b}$.
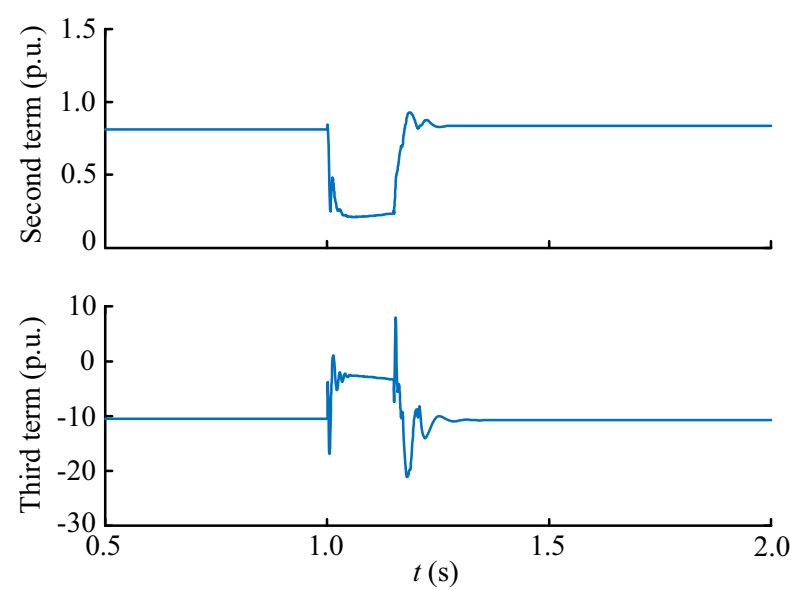

(a) Responses of sub-terms in internal voltage equation

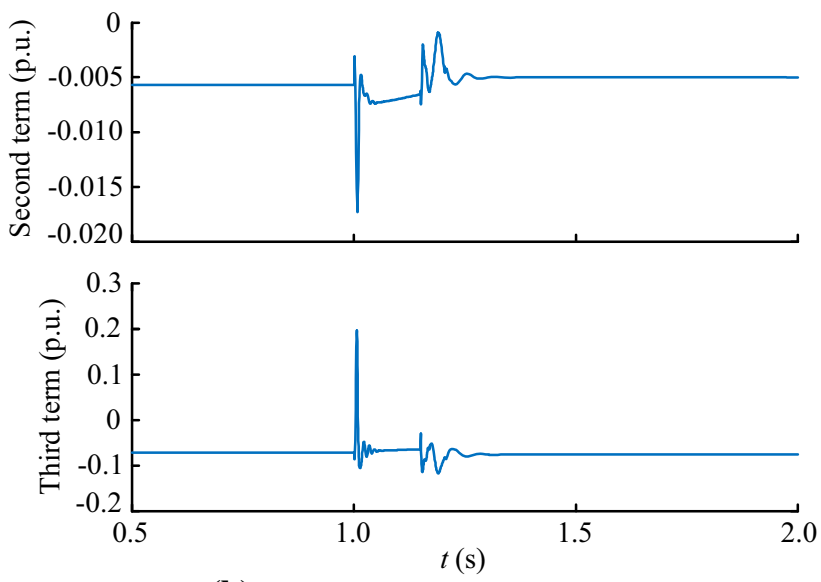

(b) Responses of sub-terms in angle equation

Fig. 5 Responses of sub-terms on right side of internal voltage and phase equations 


\subsection{Field test}

In the following, the field test is used to obtain the responses of the DFIG by a low voltage ride-through (LVRT) experiment.

\subsubsection{Experiment}

Many tests have been carried out to evaluate the fault ride-through capabilities of the WTG by provoking balanced and unbalanced faults under different operational regimes. Here the DFIG from manufacturer 1 with the parameter values shown in the Table A1 is tested and the responses are used to analyze the DFIG's dynamics.

The experimental set-up, to emulate a voltage dip, is shown in Fig. 6. The DFIG-based WTG is connected to the grid through a testing device. The testing device is designed to reduce the voltage at the DFIG terminal to a specified level within a very short time. During normal operation, a series impedance of $\mathrm{Z1}$ is connected and switch $\mathrm{S}$ is open. When switch $\mathrm{S}$ is closed and the short circuit impedance $\mathrm{Z} 2$ is connected in parallel to the DFIG, this causes a voltage dip at the DFIG terminal. After a time, switch $\mathrm{S}$ is opened and the voltage at the DFIG recovers to its original level.

\subsubsection{Responses under LVRT disturbance}

The WTG terminal voltage is shown in Fig. 7a. As $\mathrm{S}$ is closed, the voltage drops to $20 \% U_{n}$. After $\mathrm{S}$ is opened, it returns to its normal value quickly. Responses of active power and reactive power at MP are shown in Fig. 7b, and the amplitude and phase of the internal voltage are illustrated in Fig. 7 a.

The second sub-term and the third sub-term on the right side of the amplitude equation are shown in Fig. 8a; and the second sub-term and the third sub-term on the right side of the phase equation are shown in Fig. 8b.

\subsection{Contributions of $\mathrm{P}-\mathrm{A}$ model to voltage dynamic analysis}

It can be seen from the simulation and field test that:

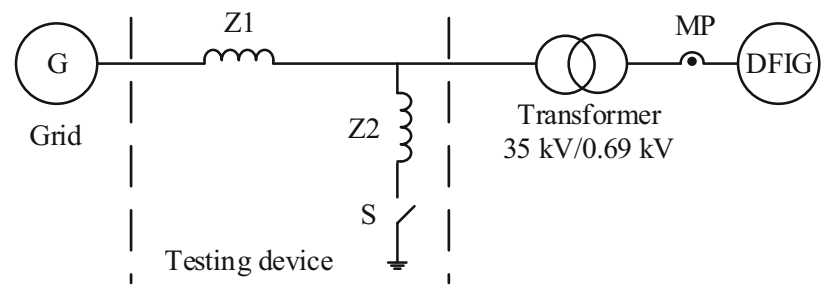

Fig. 6 Schematic diagram to emulate a voltage dip on DFIG interconnected to power system
1) During the voltage dip disturbance, the voltage magnitude and active power at MP decrease while the reactive power increases. The dynamics of the internal voltage and the terminal voltage are very similar, which indicates that the polar form model of the DFIG is suitable for analysis of the terminal voltage.

2) The magnitudes of the two sub-terms on the right side of the internal voltage equation decrease during the voltage dip disturbance. This indicates that the internal voltage is affected by the joint influence of voltage, angle, and excitation (controlled by rotor voltage).

3) The value of the third sub-term (which corresponds to the rotor voltage) in both the internal voltage and angle equations is much bigger than the values of the other two sub-terms. This indicates that the rotor voltage (or excitation) dominates the dynamics of the internal voltage and angle.
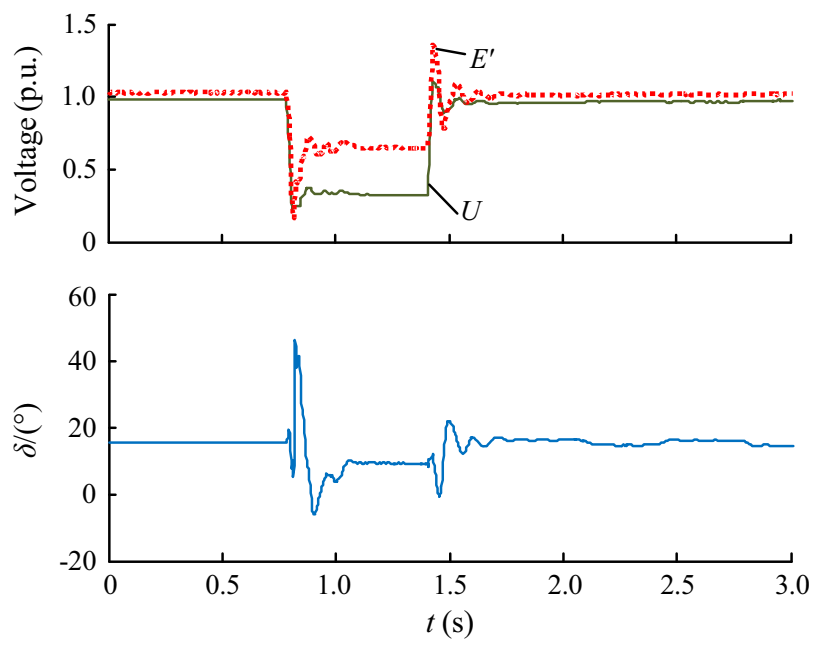

(a) Magnitude of terminal voltage and the magnitude and angle of the internal voltage

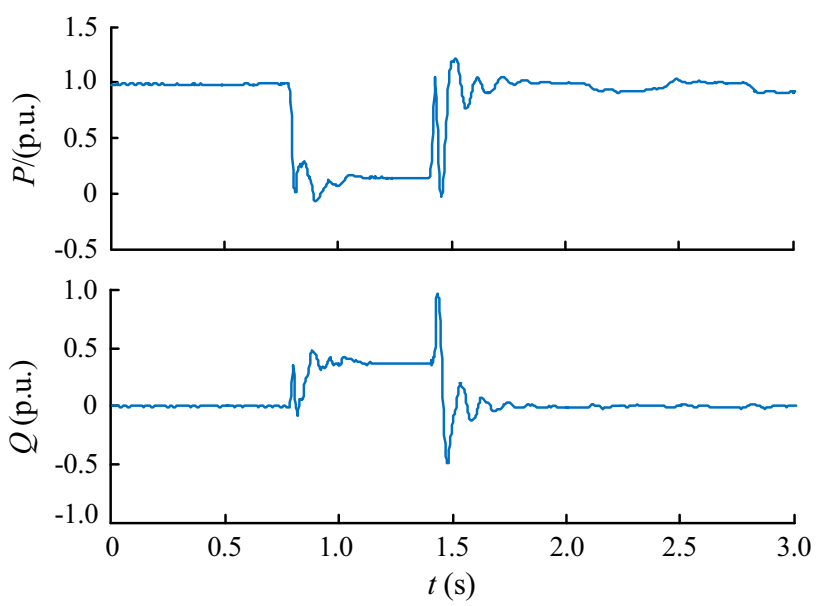

(b) Active power and reactive power

Fig. 7 Responses of DFIG at MP 

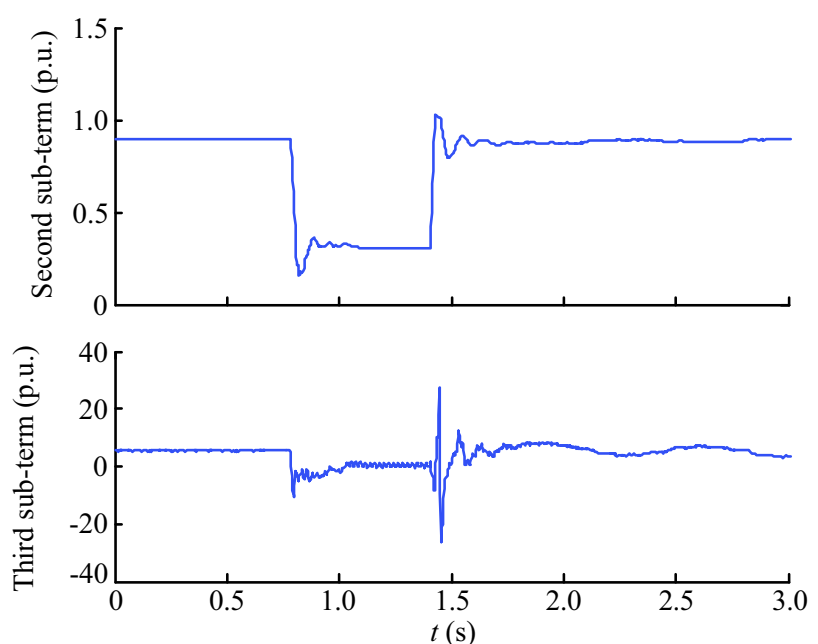

(a) Responses of sub-terms in internal voltage equation
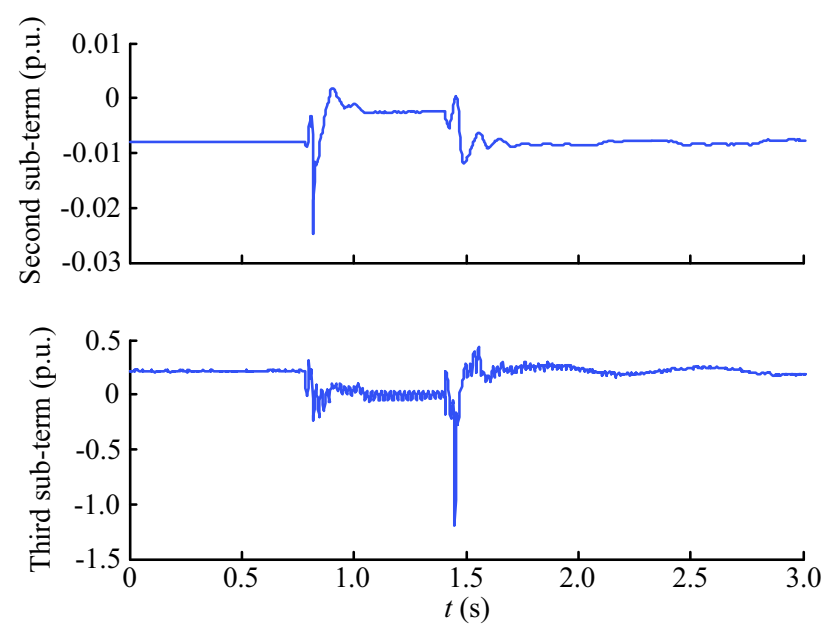

(b) Responses of sub-terms in angle equation

Fig. 8 Responses of sub-terms on right side of internal voltage and phase equations

The P-A model of the DFIG reflects the relationships between the terminal voltage and the internal voltage of the DFIG. The DFIG's dynamics are mainly controlled by the rotor voltage. Therefore, the polar form model of the DFIG can be used conveniently for power system voltage problem analysis.

\subsection{Contribution of P-A model to structural dynamic analysis}

It can be seen from Fig. 4 that after the fault is cleared, there are two dominant oscillation modes in active power trajectories; one is a slow mode, which is attributed to the drive system, and the other is a fast mode, which corresponds to the rotor electrical transients.

The measurements are in agreement with the structural analysis of (33). This indicates that the DFIG is a two-timescale model dominated by the electrical dynamics and mechanical behavior, respectively.

\section{Conclusion}

In this study, the classical models of the DFIG are illustrated and it is shown that all the existing models are expressed based on rectangular coordinates. In FMAC, the magnitude and angle of the internal voltage are often calculated based on DFIG models of rectangular coordinates. To obtain the polar form model of the DFIG, a new DFIG model based on rectangular coordinates is presented by defining the practical variables in a new manner, based on which, the polar form model is derived.

The P-A model of the DFIG demonstrates some striking similarities with the model of synchronous generators; it shows clear relations between rotor voltage and the magnitude/angle of the internal voltage.

The P-A model of the DFIG is compared with the model of the synchronous generator and the polar form model of the induction machine. The structural dynamics of the DFIG are also considered, and it is apparent that the DFIG is a two time-scale system, where the fast states are $E^{\prime}$ and $\delta$, and the slow one is $\omega_{r}$.

Simulation and a field test are used to validate the contributions of the P-A model to the DFIG. It shows that the proposed polar form of the DFIG model has better ability in describing power system dynamic phenomena, such as voltage stability and structural dynamics.

Open Access This article is distributed under the terms of the Creative Commons Attribution 4.0 International License (http:// creativecommons.org/licenses/by/4.0/), which permits unrestricted use, distribution, and reproduction in any medium, provided you give appropriate credit to the original author(s) and the source, provide a link to the Creative Commons license, and indicate if changes were made.

\section{Appendix A}

Parameter values of DFIG from three manufacturers are shown in Table A1. 
Table A1 Parameter values of DFIG from three manufacturers

\begin{tabular}{lllll}
\hline Manufacturer & Parameter values & & & \\
\hline 1 & $P_{N}=1.5 \mathrm{MW}$ & $U_{N}=690 \mathrm{~V}$ & $p=2$ & $S_{N}=1.65 \mathrm{MVA}$ \\
& $k=100.48$ & $H_{g}=70 \mathrm{~kg} / \mathrm{m}^{2}$ & $H_{t}=5259367 \mathrm{~kg} / \mathrm{m}^{2}$ & $R_{\mathrm{s}}=0.003471 \Omega$ \\
& $R_{\mathrm{r}}=0.002694 \Omega$ & $L_{\mathrm{s} \sigma}=5.557 \times 10^{-5} \mathrm{H}$ & $L_{\mathrm{m}}=0.00576 \mathrm{H}$ & $L_{\mathrm{r} \sigma}=2.02 \times 10^{-4} \mathrm{H}$ \\
2 & $P_{N}=2 \mathrm{MW}$ & $U_{N}=690 \mathrm{~V}$ & $p=2$ & $S_{N}=2.1 \mathrm{MVA}$ \\
& $k=117.66$ & $H_{g}=80 \mathrm{~kg} / \mathrm{m}^{2}$ & $H_{t}=13588930 \mathrm{~kg} / \mathrm{m}^{2}$ & $R_{\mathrm{s}}=0.002 \Omega$ \\
& $R_{\mathrm{r}}=0.001567 \Omega$ & $L_{\mathrm{S} \sigma}=3.3513 \times 10^{-5} \mathrm{H}$ & $L_{\mathrm{m}}=3.7552 \times 10^{-3} \mathrm{H}$ & $L_{\mathrm{r} \sigma}=1.544 \times 10^{-4} \mathrm{H}$ \\
& $P_{N}=1.5 \mathrm{MW}$ & $U_{N}=690 \mathrm{~V}$ & $p=2$ & $S_{N}=1.65 \mathrm{MVA}$ \\
& $k=105.6$ & $H_{g}=69 \mathrm{~kg} / \mathrm{m}^{2}$ & $H_{t}=7473111 \mathrm{~kg} / \mathrm{m}^{2}$ & $R_{\mathrm{s}}=0.00265 \Omega$ \\
& $R_{\mathrm{r}}=0.00263 \Omega$ & $L_{\mathrm{s} \sigma}=0.053 \mathrm{H}$ & $L_{\mathrm{m}}=1.72 \mathrm{H}$ & $L_{\mathrm{r} \sigma}=0.042 \mathrm{H}$ \\
\hline
\end{tabular}

\section{References}

[1] Abhilash KG, Kusum V, Khaleequr RN (2017) Dynamic impact analysis of DFIG-based wind turbine generators on low-frequency oscillations in power system. IET Renew Power Gener 11(18):4500-4510

[2] Shi LB, Su JL, Yao LZ (2017) SS resonance analysis of complex power system incorporating wind power. IET Renew Power Gener 11(3):305-312

[3] Tsili M, Papathanassiou S (2009) A review of grid code technical requirements for wind farms. IET Renew Power Gener 3(3):308-332

[4] Fan Z, Enslin JHR (2006) Challenges, principles and issues relating to the development of wind power in China. In: Proceedings of the 2006 IEEE power systems conference and exposition, Atlanta, USA, 29 October-1 November 2006, 7 pp

[5] Ekanayake JB, Holdsworth L, Wu XG et al (2003) Dynamic modeling of doubly fed induction generator wind turbines. IEEE Trans Power Syst 18(2):803-809

[6] Mei F, Pal BC (2005) Modelling and small-signal analysis of a grid connected doubly-fed induction generator. In: Proceedings of the 2005 IEEE power engineering society general meeting, San Francisco, USA, 16 June 2005, 8 pp

[7] Luna A, Lima FKA, Santos D et al (2011) Simplified modeling of a DFIG for transient studies in wind power applications. IEEE Trans Ind Electron 58(1):9-20

[8] Pal BC, Mei F (2008) Modelling adequacy of the doubly fed induction generator for small-signal stability studies in power systems. IET Renew Power Gener 2(3):181-190

[9] Ekanayake JB, Holdsworth L, Jenkins N (2003) Comparison of 5 th order and 3rd order machine models for doubly fed induction generator (DFIG) wind turbines. Electr Power Syst Res 67(3):207-215

[10] Feijóo A, Cidrás J, Carrillo C (2000) A third order model for the doubly-fed induction machine. Electr Power Syst Res 56(2): $121-126$

[11] Ellis A, Kazachkov Y, Muljadi E et al (2011) Description and technical specifications for generic WTG models-a status report. In: Proceedings of the 2011 IEEE PES PSCE, Phoenix, USA, 20-23 March 2011, 8 pp

[12] Sørensen P, Andresen B, Fortmann J et al (2014) Overview, status and outline of the new IEC 61400-27-electrical simulation models for wind power generation. In: Proceedings of 10th international workshop on large-scale integration of wind power into power systems as well as on transmission networks for offshore wind farms, Aarhus, Denmark, 25-26 October 2011, $6 \mathrm{pp}$

[13] Pourbeik P (2013) Proposed changes to the WECC WT3 generic model for type 3 wind turbine generators. https://www. powerworld.com/WebHelp/Content/Other_Documents/WECCType-3-Wind-Turbine-Generator-Model-Phase-II-012314.pdf. Accessed 30 August 2015

[14] Pourbeik P, Ellis A, Sanchez-Gasca J et al (2013) Generic stability models for type $3 \& 4$ wind turbine generators for WECC. In: Proceedings of 2013 power and energy society general meeting, Vancouver, Canada, 21-25 July 2013, 5 pp

[15] Hughes FM, Anaya-Lara O, Jenkins N et al (2005) Control of DFIG-based wind generation for power network support. IEEE Trans Power Syst 20(4):1958-1966

[16] Anaya-Lara O, Hughes FM, Jenkins N et al (2007) Provision of a synchronising power characteristic on DFIG-based wind farms. IET Gener Transm Distrib 1(1):162-169

[17] Wang Z, Sun Y, Li G et al (2010) Magnitude and frequency control of grid connected doubly fed induction generator based on synchronised model for wind power generation. IET Renew Power Gener 4(3):232-241

[18] Yuan H, Yuan X, Hu J (2017) Modeling of grid-connected VSCs for power system small-signal stability analysis in DClink voltage control timescale. IEEE Trans Power Syst 32(5):3981-3991

[19] Zhao M, Yuan X, Hu J (2018) Modeling of DFIG wind turbine based on internal voltage motion equation in power systems phase-amplitude dynamics analysis. IEEE Trans Power Syst 33(2):1484-1495

[20] Ju P, Huang H, Jin YQ et al (2015) Potential angle model of doubly fed induction generator (DFIG) and derivation method of potential angle model. CN104993757A

[21] Li S, Challoo R, Nemmers MJ (2009) Comparative study of DFIG power control using stator-voltage and stator-flux oriented frames. In: Proceedings of the IEEE power and energy society general meeting, Calgary, Canada, 26-30 July 2009, 8 pp

[22] Kundur P (1994) Power system stability and control. McGraw Hill, New York

[23] Ahmed-Zaid S, Taleb M (1991) Structural modeling of small and large induction machines using integral manifolds. IEEE Trans Energy Convers 6(3):499-505

[24] Hiskens IA (2012) Dynamics of type-3 wind turbine generator models. IEEE Trans Power Syst 27(1):465-474

[25] MATLAB user's guide-dynamic system simulation for MATLAB. The Math Works Inc 
Hua HUANG received the B.E. degree in electrical engineering from Hohai University, Nanjing, China, in 2011 and the M.S. degree in electrical engineering from the University of Strathclyde, Glasgow, UK, in 2012. Currently she is pursuing the Ph.D. degree in Huazhong University of Science and Technology, Wuhan, China. Her research interests include modeling and control of renewable power generation systems.

Ping JU received the B. E. and M.S. degrees from Southeast University, Nanjing, China in 1982 and 1985, and the Ph.D. degree from Zhejiang University, Hangzhou, China in 1988. From 1994 to 1995, he was an Alexander von Humboldt Fellow at the University of Dortmund, Germany. He is currently a Professor of Electrical Engineering at Hohai University, Nanjing, China. He has published five research books and authored and coauthored over 200 journal papers. He received the Scientific Funds for Outstanding Young Scientists of China. His research interests include modeling and control of power systems.

Xueping PAN received the Ph.D. degree from Zhejiang University, Hangzhou, China, in 2008. She is presently a professor in the College of Energy and Electrical Engineering, Hohai University, Nanjing, China. Her research interests include modeling of renewable power generation system, power system dynamic analysis.
Yuqing JIN received the B.E., M.S. and Ph.D. degrees in electrical engineering from Hohai University, China, in 2002, 2006 and 2012, respectively. Currently, he is an Associate Professor in the College of Energy and Electrical Engineering at Hohai University, China. His research interests include modeling and control of renewable power generation.

Xiaoming YUAN received the B.E. degree from Shandong University, China, the M.E. degree from Zhejiang University, China, and the $\mathrm{Ph}$.D. degree from Federal University of Santa Catarina, Brazil, in 1986, 1993, and 1998 respectively, all in electrical engineering. He is a Distinguished Expert of National Thousand Talents Program of China, and Chief Scientist of National Basic Research Program of China (973 Program). His research interests include stability and control of power system with multi-machines multi-converters, control and grid-integration of renewable energy generations, and control of HVDC transmission systems.

Yuan GAO received the M.E. degree from Hohai University, Nanjng, China, in 2015. He is presently an engineer in State Grid Jiangsu Electric Power Maintenance Company. His research interests include modeling of wind power generation system. 